\title{
Detecting Passage of Migrating Woodcock Using Nano Tag Technology
}

D. G. MCAULEY, ${ }^{1}$ U.S. Geological Survey, Patuxent Wildlife Research Center, 17 Godfrey Dr., Suite 2, Orono, ME o4473, USA

R. E. BROWN,,$\underline{2}$ U.S.F.W.S. Northern Maine National Wildlife Refuge Complex, Moosehorn National Wildlife Refuge, 103 Headquarters Rd, Baring, ME 04694,USA

ABSTRACT: Nano tags are regular VHF radio transmitters that broadcast on a single frequency that is encoded. Signals are picked up by towers and stored. Data can be stored at the tower for several months and then downloaded. After downloading, data are sent to Canada to be sorted and then sent to the individual researchers. Costs of the nano tags are the same as conventional VHF transmitter projects (about \$210.00). The cost of the receiver is about $\$ 300$. Currently there are about 564 receiving towers, mostly along the Atlantic coast, and 30 different projects, although the system can handle more studies. The data can be used to study movement patterns, migration timing, and speed, and also to give survival estimates. Birds do not need to be followed on the ground or from the air. Transmitters range in weight from 0.26 grams to 4.3 grams, and have a life expectancy of 10 to more than 11,00o days. We used the 4.6-gram transmitters with a life expectancy of 405 days.

In 2015 we deployed 24 transmitters at Moosehorn NWR during late September and October. We were interested in timing of migration and stopovers. Ten transmitters were detected in CT at 2 different towers. One bird was picked up by both towers, 2 were detected in RI, 1 at Plum Island on Long Island, NY, 3 at Cape May, NJ, and 2 at the Eastern Shores of VA NWR. Data from 2017 will be presented as well.

Proceedings of the American Woodcock Symposium 11: 263

KEY WORDS: American woodcock, Atlantic Coast, migration, nano tag

1 email: dmcauley@usgs.gov

2 email: ray_brown@fws.com 